\title{
Public Personnel Training
}

\author{
Dr. S. B. M. Marume ${ }^{1}$, \\ ${ }^{I}$ BA, Hons BA, MA, MAdmin, MSocSc, PhD Department of Public Administration Zimbabwe Open \\ University
}

\begin{abstract}
Public personnel training, which is essentially an aspect of public personnel administration in public administration, is most pertinent to Africa, especially southern Africa. This is so because the nascent black nations are in peculiar circumstances as they are all characterized by enormously rapid changes in nearly every area of society. The attainment of independence from impervious imperial Portugal by Angola and Mozambique in 1975; Zimbabwe in 1980 from colonial Great Britain; Namibia in 1990 from being a disputed United Nations mandated territory since 1919; and majority rule government by South Africa in 1994 after many years of foreign rule and domination and also after protracted bloody armed struggles waged by African nationalist movements; brought in its train dramatic changes. At independence in all these countries the situation was further acerbated by the conspicuous absence of experienced black public administrators and other essential personnel at the top level positions in the respective public services, who could have immediately been placed at the centres of the transformation programmes of their civil services from what they were at independence; ensuring their rapid Africanization but without necessarily compromising on effectiveness, efficiency and systems and best practices. The job of transforming of the public services as well as societal changes was no mean task given the racially entrenched white colonial ethos which had clearly made the public services, namely, the civil services, judicial services, police and prison services as well as defence services, key levers of settler rule, black discrimination and oppression. This situation had led also to momentously innumerable issues, problems and challenges as well as presenting boundless opportunities and prospects due to rapid Africanization initiatives. Inevitably, public institutions needed to be reorganized, or re-shaped and many more new ones created in order to attend to and address specific needs arising from this situation. Key personnel were needed to be appointed to critical positions at the centres of service delivery, responsible for coordinating and helping in drafting major policy matters which could assist the new Government to record milestones, which included reconciliation, reconstruction, rehabilitation and re-integration of hundreds of thousands of war displaced people as well as massively embarking upon major successive socio-economic transformation programmes which underpinned their espousal, dedication and commitment to majority rule government and administration. Therefore, the public personnel who were to be responsible for all these unprecedented multifarious activities of the various governmental institutions, urgently needed to possess the extraordinary talents, wisdom, direction, dedication, knowledge, proper skills, capabilities, insights, appropriate attitudes, behaviours and habits to be in a position to deal with these daunting challenges; and to be bold enough to confront them squarely head on. Training of public personnel became and still is a sine qua non.
\end{abstract}

Keywords:- public personnel training, rapid change, innumerable issues, necessary knowledge, proper skills, appropriate attitudes, habits and behaviours.

\section{INTRODUCTION}

"You cannot teach a man anything. You can only help him discover it within himself'

From reviews of related literature on public personnel administration, most particularly public personnel training, the on-going training and development of public officials is vital to create a favourable climate in which the human resources of public institutions as learning organisations are 
capacitated to address environmental problems and challenges. Public personnel administrators and managers should make profound contributions in this regard.

Public personnel training and development implies the expansion of knowledge frontiers, the acquisition of skills and the positive changing of patterns of behaviours, habits and attitudes. This inescapably involves a learning process in which information is obtained and processed. People in a learning process can hardly remain unchanged or unaffected. In this study whose methodology is basically descriptive-analytical-explanatory in nature, we intend to define, examine, discuss and evaluate training and development in the public sector with specific reference to the role of public personnel administrators and managers in Southern Africa.

\section{PURPOSE OF ARTICLE}

The purpose of this article which is multiple is to: define, examine, explain the role of and demonstrate the necessity for training and development in the public sector as well as to outline the role of the public personnel administrators and mangers with reference to Southern African nations as one the group of developing countries - societies in transition experiencing countless developmental issues, problems and challenges occasioned by dramatic changes unprecedented in the history of Africa.

\section{PUBLIC PERSONNEL TRAINING AND DEVELOPMENT}

The under mentioned aspects are relevant to understanding the issues regarding public personnel training and development in Africa generally and Southern Africa in particular.

\subsection{Prominent social scientists, writers and scholars}

Authorities relevant to public personnel training include:

\begin{tabular}{|c|c|c|}
\hline $\begin{array}{ll}\text { - } & \text { O. Glenn Stahl } \\
\text { - } & \text { S. P. Robbins } \\
\text { - } & \text { F. A. Nigro and L. G. Nigro } \\
\text { - } & \text { D.K. Wheeler } \\
\text { - } & \text { G. B. Siegel }\end{array}$ & $\begin{array}{ll}- & \text { J. J. N. Cloete } \\
\text { - } & \text { N. J. Powell } \\
\text { - } & \text { W. Fox } \\
\text { - } & \text { S.B. M. Marume } \\
\text { - } & \text { B. J. Roux }\end{array}$ & $\begin{array}{ll}- & \text { P. S. Botes } \\
\text { - } & \text { Y. Andrews } \\
\text { - } & \text { D. D. Riley } \\
\text { - } & \text { D. S. Beach } \\
\text { - } & \text { D. F. S. Fourie }\end{array}$ \\
\hline
\end{tabular}

\subsection{Terminological uses}

Here we refer to four relevant terms and concepts; namely trainees, learning, training and development throughout this article. We hope to benefit immensely by becoming familiar with their universal meanings.

\subsubsection{Public personnel as trainees}

For our purposes, public personnel refer to people appointed in the public sector who perform certain functions in the public services. In the context of training, students or course participants refer to the personnel of public institutions who undergo training to acquire knowledge, skills or abilities or competencies, patterns of behaviour, habits and appropriate attitudes.

\subsubsection{Learning}

Where a manager fails to learn, he or she will be unable to see, hear or feel properly in order to use his or her other management tools

Source: Peter Stannack, 1993

From refated literature reviews and on the basis of personnel training experiences, learning is viewed as a complex process in which impressions are gained and processed, resulting in the expansion of knowledge. Learning requires a deliberate effort from the learner and, in this case, the public official. Learning here focuses on the discussion and evaluation of the theory and principles of learning, with specific reference to their role in the training and development processes applied in the governmental institutions. Numerous views exist on what learning actually is, and learning theorists also have their own opinions on different learning theories. Learning theory probably 
originated with Plato, 500 years BC. Plato claimed that at birth, children have potential ideas and that the senses have an effect on these ideas. He said that learning takes place through thought and reasoning. However, this learning theory denies the role of the senses and learning content $(\mathbf{C} \mathbf{d u} \mathbf{T}$. Oliver, 1986: 49-53).

Locke (In Oliver, 1986) states that learning consists purely in gaining impressions from the outside on a blank conscience. Complex knowledge is expanded on the basis of an internal sense which people have. The shortcoming in this learning theory is that people's own inputs and learning performances are overlooked.

Skinner (in Oliver, 1986: 49-53) describes learning as interaction between a stimulus (teaching) and a response (learning). He refers to the process that takes place as perceptual behaviour as a result of the umbrella role of the senses. Each new stimulus has some relationship with previously processed stimuli and learning is, therefore, a stimulus reaction event.

\subsubsection{Training}

The question that needs to be answered is: what actually is training? S.B.M. Marume (1977) maintains that training can be viewed as (a) an active action process; (b) by means of which capabilities of the public servants can be improved; (c) in order to meet the institutional needs in terms of their knowledge, skills and attitudes required in performing institutional tasks and functions; and (d) Within a reasonably short period of time. From personnel training experiences, as chief training officer of Governmental training institutions, training has been defined to mean the process of developing competencies, skills, habits, knowledge and attitudes in public employees for the purpose of increasing the effectiveness of employees in their present government positions as well as preparing employees for future government positions. [Marume: 1988].

Marume [1977, 83 and 1988] states that training is viewed as purposefully articulated effort exerted in order to provide for an increased capability in the public services, by imparting professional knowledge, broader vision, and correct patterns of behaviours, habits and attitudes, on a continuous process in direct response to a continuously felt need. Therefore, from comparative related literature reviews, training can be authoritatively defined as all those systematically planned and purposeful activities which are intended to improve the knowledge, skills, capabilities, abilities, insights, attitudes, behaviours, values and working and thinking of public servants or prospective public servants in such a manner that they are able to perform intended or designated tasks and responsibilities more efficiently and effectively (Marume, 1985 and 1988). This can all be achieved through education, development, lecturing, teaching, training and re-training, and consultancy support programmes.

\subsubsection{Development}

Y. Andrews (1988:140) defines development as a continuation of education and training for the purpose of acquiring sufficient experience, required knowledge, skills and the right attitudes to be appointed to the highest appropriate administrative and managerial positions.

Management development can also be defined as: “....... the planned process of ensuring through an appropriate learning environment and experience the continuous supply and retention of efficient managers and administrators at all levels to meet the requirements of an organisation and enhance its strategic capacity" (R. Harrison, 1995, 326). In this article we employ the term development to indicate the additional knowledge, skills and attitudes that individuals need to enable them to:

(a) perform better than the minimum requirement in their current position;

(b) become skilled enough to fulfil other future positions at the same or higher levels in the public sector, and

(c) Be able to maintain the higher level of performance requirement.

\subsubsection{Distinctions between training and development}

The concepts of training and development are quite often confused. However, principal differences can be identified: 
Public Personnel Training

\begin{tabular}{|l|l|}
\hline Training & Development \\
\hline 1. focuses on current needs & 1. focuses on projected needs \\
\hline 2. is task oriented & 2. is personnel oriented \\
\hline 3. is directed at specific job requirements & 3. is directed at institutional requirements \\
\hline
\end{tabular}

\subsection{Place, role and objectives of public personnel training}

According to literature available, the role of training for public servants has been studied and thoroughly analyzed in countries such as the United States of America, Australia, the United Kingdom, France, Holland, and others. On the training objectives, it has been stated: that in any large scale organization, efficiency depends on two elements: (a) the technical efficiency of the individual to do the particular work allotted to him/her, and (b) the less tangible efficiency of the institution, as a corporate body, derived from the collective spirit and outlook of the individuals of which the body is composed. Training must have regard to both elements, the five distinct general training objectives, according to various studies are summed up as follows:

(a) To produce public servants who can transact their business with precision and clarity.

(b) To attune the public servants to the tasks they are called upon to perform in a changing world. The public servants must continuously and boldly adjust their outlook and their methods to the new needs of the new times.

(c) To make the public servants community conscious. There is a need to develop resistance to the danger of the civil servants becoming mechanized by the machine; whilst we must aim at the highest possible standard of efficiency. Our purpose is not to produce a robot like, mechanically perfect public service.

(d) To develop the capacity of the public servants for higher work and greater responsibilities.

(e) To improve the morale of the public servants.

However, the following can be added to the above list of training objectives:

(f) To make up for the deficiencies of new entrants to the public service.

(g) To broaden the vision and outlook of the public servants.

(h) To promote integrity in the public servants.

(i) To promote spirit de corps in the employees.

(j) To inculcate the attitude that a civil servant is not a master but a public servant.

According to Herbert A. Simon, a world renowned public administration scientist, the following three factors have given particular urgency to the training of civil servants in developing countries:

- The need for innovation, imagination and creativity in public administration to meet the demands and challenges of our times.

- The rapid multiplication of government tasks and duties.

- The acute shortage of skilled manpower resources.

These general training phenomena and theories are also applicable to the specific circumstances of the particular countries in southern Africa where there is the noticeable urgent need to continuously train public personnel for increasingly higher work and greater responsibilities arising out of structuring and restructuring and reforms of the public services of these developing countries.

\subsection{The necessity for and advantages of training and development of public personnel} The pertinent questions that arise from this topic include: what is precisely the necessity for and what are the distinct advantages of training and development of public personnel?

\section{Possible answers:}

Clearly, there is no argument regarding the necessity for formal measures for training and developing public employees. The factors demanding that well-planned formal training be given to public officials to meet certain training needs are summed below by acknowledging the commendable scholarly contributions of two eminent social scientists: J. J. N. Cloete (1990) and D. S. Beach (1985). According to J. J. N. Cloete (1990: 135-136),

(a) personnel come to the work situations molded by their origins and environments. they arrive with patterns of behaviour, views, attitudes and prejudices which might not fit into their working circle at all. The public sector requires patterns of behaviour and attitudes which are 
in line with the basic ethical principles of public management and which make a moral elite of public officials.

(b) circumstances today require all employees to learn how to behave in the work environment, for example, how to handle equipment, to manage time, comply with regulations, and follow prescribed procedures.

(c) the work of public institutions changes constantly and formal learning will enable personnel to adjust to changing circumstances to the most beneficial way.

(d) some occupations are found only in the public sector and personnel, therefore, need to be trained to perform that specialised work.

(e) the theories and practices of public administration and management change continually and periodic training is needed to keep personnel abreast of new developments.

(f) the morale of personnel can be improved and their loyalty maintained through formal training rather leaving personnel to their own devices without any guidelines

(g) training ensures that all officials understand their contribution to the institution and personnel objectives can thus be reconciled with the institutional objectives.

According to D. S. Beach (1985:244), administrative and management training has both direct and indirect advantages for institutions. These advantages are briefly stated as follows:

(a) Training reduces the learning time needed to achieve an acceptable level of performance; and by means of having qualified instructors in controlled learning situations, management can succeed in reducing the learning time and obtain higher productivity from new employees.

(b) Training improves the job performance of the incumbent and training is not only for new personnel but also for experienced personnel.

(c) A common objective of training programmes is to try to create new positive attitudes or changing existing ones. Training is directed in support of the instruction's objectives; and can lead to better cooperation and greater loyalty

(d) Training can help to solve operational problems and challenges.

(e) Training helps to meet the need for human resources and it means that an institution always has enough suitably qualified and skilled human resources.

(f) The employees themselves can benefit from training; as they acquire new knowledge and skills, they become more competitive and raise their levels of income. These skills in turn increase their job performance excellence and job security. Training may also help employees to qualify for promotion and more responsible tasks.

To gain the most from administrative and management training and higher qualifications, the training must address direct issues in the institution and be based on the institution's aims and objectives. Training aims and objectives must, therefore, coincide with those institutional aims and objectives. In sum, the advantages of training and development in the public services can be divided into three broad categories as shown below.

\subsubsection{Advantages for the community/society}

Training not only benefits the community or larger society by giving it greater stability but also reduces poverty and raises the general standard of living. By training and developing public officials, the state is ensuring that the needs of the community are met and that scarce resource are used optimally to the benefit of the whole community. Training and development can also increase the quantity and quality of public services and/or products provided by public institutions.

\subsubsection{Advantages for the state as an employer}

From available literature, it is argued that by training and developing personnel, employees can ensure that the products and/or services constituting their purpose are provided economically, efficiently and effectively. This may lead to the expansion of products and/or services and thus increase public funds, which in turn can improve job productivity and increase a stable labour force in which 
personnel, are satisfied and motivated. Employees then perceive the state as a good employer increasing sense of loyalty, security and willingness and commitment to duty.

\subsubsection{Advantages for public employees}

From literature reviews, it is maintained that training and retraining is valuable not only to the country as such but also to individual potential workers. Training helps to address personal poverty because personnel members increase their knowledge, skills and attitudes. They also improve their personal income and their competitive positions in the labour market. Training protects individual workers from unemployment- unemployment occasioned particularly technological, scientific and structural advances. Against the background of the above factors, we now discuss training in the public sector as part of responsibilities of public personnel administrator and mangers.

\subsection{Public administration and management training}

According to D. K. Wheeler (1976):

"Education is what remains when the facts are forgotten"

People can be viewed as the most important resource of any institution. This is augmented by the following:

The availability of physical resources, finances, infrastructure, machines and equipment, buildings, technology and information is of no consequence without a well trained, efficient, motivated and effective workforce to provide the relevant services to clients. This is particularly so in public service institutions where the rendering of public goods and services to the community or society at large takes place in the context of scarce resources and increasingly competing societal demands. People are responsible for policy formulating, organising the institutions to achieve aims and objectives and providing important products and services to the public. To perform these activities, well-trained personnel are vitally important. It is necessary first to discuss: a systems approach to training and then we consider the advantages of training; the connection between training and institutional aims and objectives; the typologies of training and the determination of training needs.

\subsubsection{Systems approach to public personnel training}

The basic premise is that people are complex beings and hence public administration is increasingly changing from a government orientation to a systems and multidisciplinary orientation. Thus the systems approach to training is probably best illustrated by the diagram below. Figure 1.1 is intended to provide an overall perspective of the place of training and development in the broad field of human resource management [also public personnel administration].

\section{Figure 1.1: The place of training in human resources management}

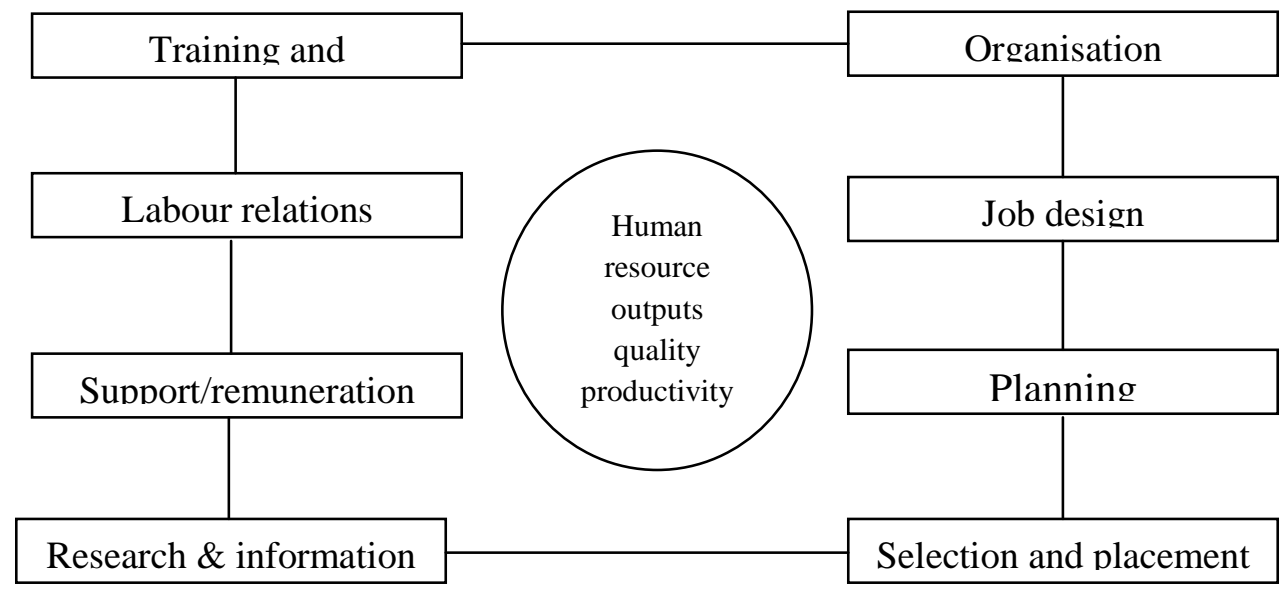

Source: Adapted from Brinkerhoff (1988:27) 
- These eight human resources subsystems are constantly interacting with and influencing one another.

- The figure above also shows that training is only one of the subsystems and that the complex environment of training should always be taken into account.

\subsubsection{Determining training needs}

- Changing circumstances themselves make training indispensible and also training must focus on meeting real specific needs.

- Training needs must be defined in terms of the institution's aims and objectives so that training can ultimately make the greatest contribution possible to increased work productivity and effectiveness.

- other reasons for determining training needs on an ongoing basis include those listed below:

$\boldsymbol{\nu}$ training that is not real on actual needs inevitably leads to ineffective use of time, effort and money;

$>$ the success of the institution depends on the optimal use of human resources and this means determining and meeting individual training and development of needs.

$>$ institution and the composition of their personnel are changing increasingly rapidly.

$>$ needs determination is critical because of the potential impact that training has on the institution; and hence effective training can contribute significantly to quantity and quality public services.

$>$ public administrative styles and perceptions adapt to changing circumstances.

Before public personnel training commences certain definite steps should be taken to establish the precise training and development needs of the institution. In this connect, J. J. N. Cloete (1990:139) eminently and succinctly makes the following contributions:

(a) when the tasks to be done are properly identified, described, analyzed and evaluated for the purposes of creating jobs, the educational qualifications and other relevant skills that the incumbents must have to do the work are determined; and once these have been established, a major part of the determination of training needs has been completed.

(b) the factors creating the training needs be analyzed, and a few of these factors are outlined below:

\section{Factors that create training needs:}

- behaviour patterns, attitudes and views of personnel which must be adapted to conform to certain work circumstances.

- $\quad$ training provided by educational institutions does not meet felt the needs of the organisation concerned.

- $\quad$ mobility of personnel.

- $\quad$ continual change in methods and/procedures.

- $\quad$ changing circumstances and policy

Cloete (1990: 139) further states that to determine other training needs, one or more of the following indicators can be used:

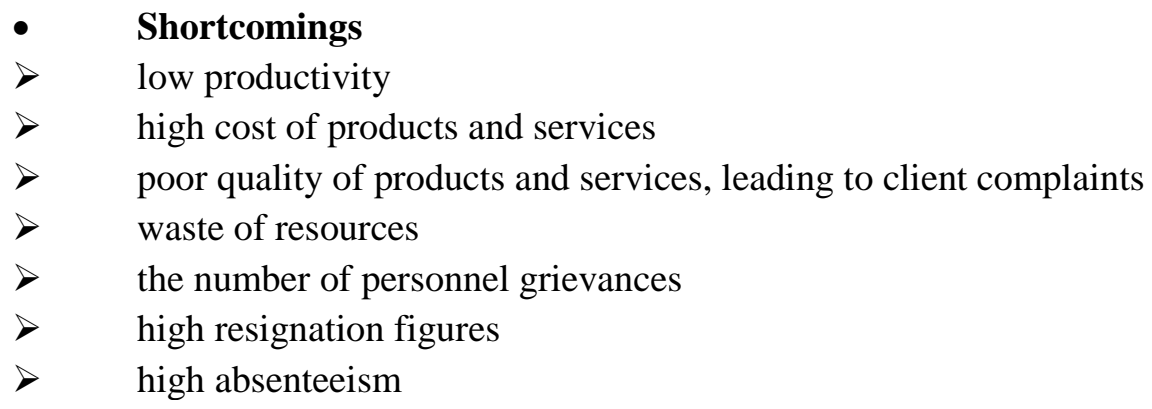

$>\quad$ high absenteeism 
- Obtaining the opinions of personnel and supervisors

$>$ standardized interviews with personnel members, supervisors and trainers to determine training needs.

$>$ commissions or committees of inquiry that obtain the views of personnel and supervisors.

$>$ requests to staff associations and trade unions to use the measures for joint consultation on training needs and arrangements to meet these needs.

- Evaluation of posts, grades and incumbents

$>$ job evaluation

$>$ testing personnel members to establish whether they have the required knowledge, skills and appropriate attitudes.

$>$ administrative and management audits or human resources audits to establish gaps between personnel requirements and the personnel available.

\section{- Provision for future needs}

$>$ new work methods and procedures.

$>$ acquisition of new equipment

$>$ new activities to provide new products and /or services.

$>$ provision for technological and scientific developments and advances.

$>$ organisational changes such as restructuring or amalgamation or creation or abolition of departments.

$>$ provision for future demands for skilled manpower resources.

- Training must be directed at meeting the institution's needs and achieving its aims and objectives.

- A mathematical model can also be used to determine training needs: $\mathrm{PD}=\mathrm{M}-1$

Here PD refers to performance deviations, $\mathrm{M}$ stands for all the knowledge, skills and attitudes needed to perform the tasks and I to the skills, knowledge and attitudes that personnel already have. Therefore PD equals the training needs that should received attention through training.

\subsubsection{Levels of public personnel training needs}

In my experience in dealing with issues of developing societies in Africa, two categories of training can be advocated; namely, (a) at policy deciders level and (b) at policy implementer's level.

\subsubsection{Policy decider's levels}

This level involves various public policy deciders as political leaders of communities such as: newly elected parliamentarians at national level

- cabinet ministers

- newly elected provincial and metropolitan council chairpersons committee chairpersons and councillors

- newly elected local councillors for both urban and rural authorities.

Experience has it that almost all of these members come to be elected to these public policy making offices without a clue of how these positions function. There is massive trial and error in which the office-bearers exercise the various public responsibilities and yet the public is expecting high standards of performance from these office bearers who are struggling to find their feet in the new political offices. Training of these members is therefore, necessary - to equip them to discharge their responsibilities.

\subsubsection{Pure public personnel level of training needs}

Important public administrators in the public services include:

- permanent secretaries who are the departmental heads as accounting officers 
- deputy permanent secretaries who heads divisions of government departments as executive institutions

- under and assistant secretaries in charge of units

- various grades

- professional staff

- executive and clerical divisions

- supervisors and workers.

Three main levels of training needs can be identified: individual, occupational and organisational level

\subsection{Individual level}

Training needs at individual level refer to shortcomings in job behaviour, that is, knowledge, skills and attitudes. Personnel administrators and managers should gather pertinent information about those individual who experience specific shortcomings in terms of knowledge, skills and attitudes. Research techniques can be used in this analysis, for example, observation; questionnaires; and interviews.

\subsection{Occupational level}

At this level, the focus is not on the individual, but on the job or occupation. A job analysis is carried out and, on the basis of this analysis a job description and a job specification are compiled. This process is illustrated in figure 1.2

At occupational level information is gathered on: proper knowledge; required skills; and appropriate attitudes required in a specific occupation.

Figure 1.2 Scope of job analysis

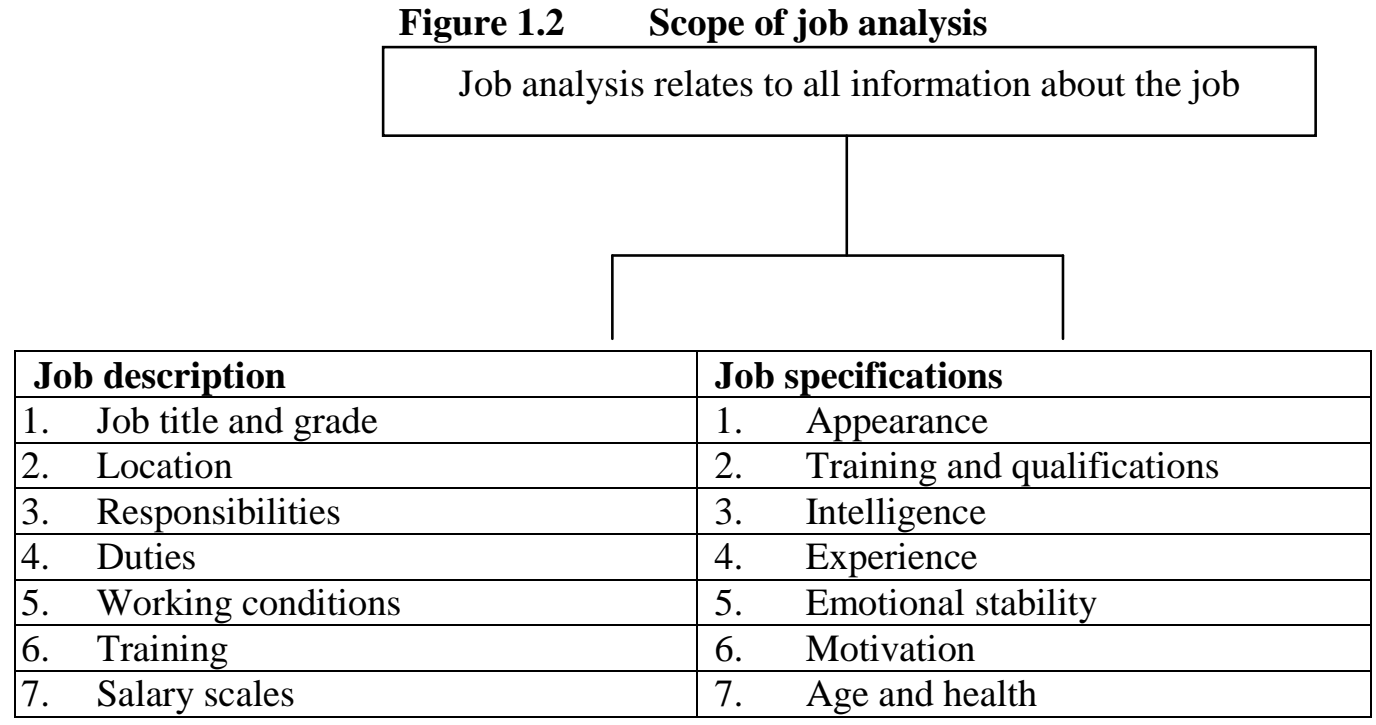

Note: Job description and job specifications which guide recruitment must be done first before appointments to the position are made.

\subsection{Organisational level}

(a) At this level, the institution is analyzed as a whole. shortcomings and general deficits are identified at each level of each division of government department or institution and at each occupational level such as:

- departmental permanent secretary's level,

- deputy permanent secretary's level

- $\quad$ under secretary's level 
- $\quad$ middle management

- supervisory levels and so on.

(b) The shortcomings thus identified are then addressed by training.

(c) Experience has it that at organisational level, external trainers as consultants are often used to identify shortcomings.

(d) The general reasons for the use of external consultants are that they are widely experienced and impartial towards the institution and can thus identify shortcomings in an objective way.

For example, in Zimbabwe soon after the announcement of the Africanization policy of the public services in 1981, the British Overseas Department was tasked to carry out most of the Zimbabwe civil service training.

The same goes for the civil service training for Angola and Mozambique which was carried out by external consultants from Portugal, Norway and Sweden. In the case of black South Africa, the Commonwealth played pivotal training and consultancy roles to help shape the civil services of the nascent of black South Africa and Namibia.

\subsubsection{Typologies of training}

We can identify the following types of training: orientation training and proficiency training

Orientation training

Orientation training is essential for any newly appointed person who may have the right academic qualifications, but may not be familiar with the specific circumstances and skills of the new job. The following aspects must be conveyed in this person through training:

$$
\begin{aligned}
& \text { - } \text { conditions of service } \\
& \text { - } \text { absence with or without leave. } \\
& \text { - the institution's activities, aims and objectives and where the person fits in } \\
& \text { regarding the achievement of these aims and objectives }
\end{aligned}
$$

According to Y. Andrews (1988:146), the most important objectives of orientation training are:

- to cut costs by orienting new appointed persons quickly to an unfamiliar work environment;

- to prevent personnel turnover caused by negative influences and a sense of inadequacy among new administrators and managers;

- to save time, since higher- level administrators do not need to spend as much time on training new people; and

- to eliminate mistakes and to establish more positive interpersonal relations.

Induction differs from orientations because it is directed at the job for which the person was employed.

Training at this stage must take place through the demonstration technique.

The emphasis is placed on the why. This is important to ensure that the person understands the reasons behind certain activities and can thus work more purposely.

\subsubsection{Proficiency training}

Skills refer to, among other things, the human, conceptual, technical, cognitive, appreciative, analytical, and communication competencies, that people have. Training is needed to apply these skills correctly in practice. Because modern governmental activities are so complex and diverse, each public institution may use different processes and methods requiring unique proficiency training. According to Y. Andrews (1988:152-154), the following methods are used to present proficiency training: 
- classroom education;

- workbench training;

- simulation or imitations, including case studies, experimental exercises and computer models, for instance, CD-ROM.

- vestibule training

The ability of administrators and managers to be sensitive to personnel needs is particularly important in that the cause of ineffective job performance lies in emotional problems and challenges. Sensitivity training emphasizes the emotional aspects of training, focusing on improving interpersonal relations specifically.

\subsubsection{The relationship between public institutional objectives and training objectives}

In modern times, public institutions in both developed and developing African societies have to structure and plan training in such a way that the institutions' aims and objectives can be achieved. Training should meet the following criteria:

(a) It should be based on the concept that it must make an economic contribution to the institution providing the personnel for training.

(b) It must be founded in the management process - it is not an additional or peripheral function, but a way of getting work done.

(c) It must make an appreciably measurable contribution to the institutions' aims and objectives. These training requirements make complex yet challenging demands of public personnel administrators and managers to ensure that training managers to ensure that training is efficient and effective.

\subsubsection{Training interventions}

In considering training interventions it is pertinently relevant to analyze the role that personnel administrators and managers play.

The arguments are that:

(a) personnel administrator and managers usually liaise with personnel supervisor to develop the most appropriate training for new governments.

(b) personnel administrators and managers are, therefore, indirectly responsible for training personnel so that they can carry out the duties and responsibilities they are charged with economically, efficiently and effectively.

(c) personnel administrators and managers must utilize the training process because they:

- $\quad$ are familiar with the work that needs to be done;

- $\quad$ know what is expected of each employee;

- $\quad$ are in close contact with employees and understand their job expectations;

- $\quad$ are in a favourable position to determine each employee's training needs.

(d) although personnel administrators and managers perform a staff function and, therefore, have no line powers, they can intervene if training needs arise. this intervention is known as training intervention.

(e) a systematic formal training process as part of the training intervention is essential to ensure orderly training. The various steps in the training process do not necessarily follow one another, but they can be represented as follows: 


\section{Figure 1.3}

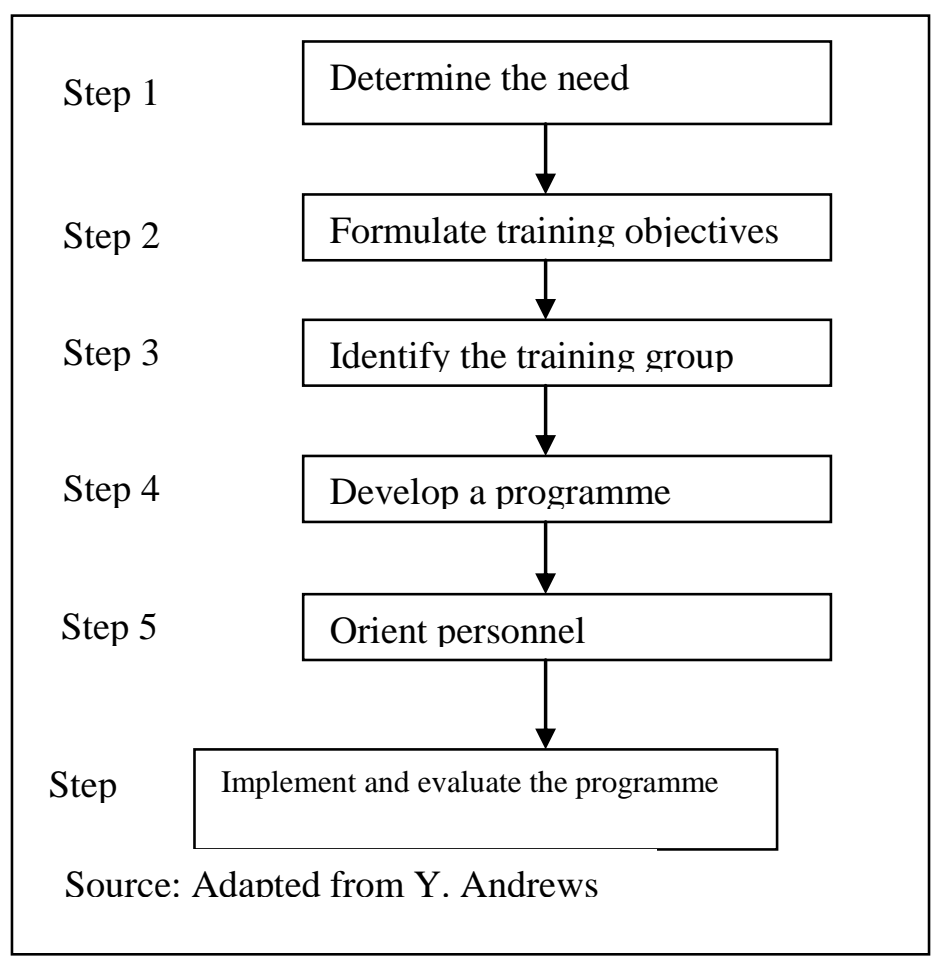

(f) We need to briefly discuss the various steps so that an overall picture of the training interventions cycle can be better appreciated.

\subsubsection{Determine the public personnel training needs}

This is the first step in the training intervention; and the training need can be defined as the difference in the way in which tasks are expected to be carried out in the future and the way in which they are actually being carried out in the future and the way in which they are actually being carried out at present. We can show this as follows:

Figure 1.4: Determination of training needs.

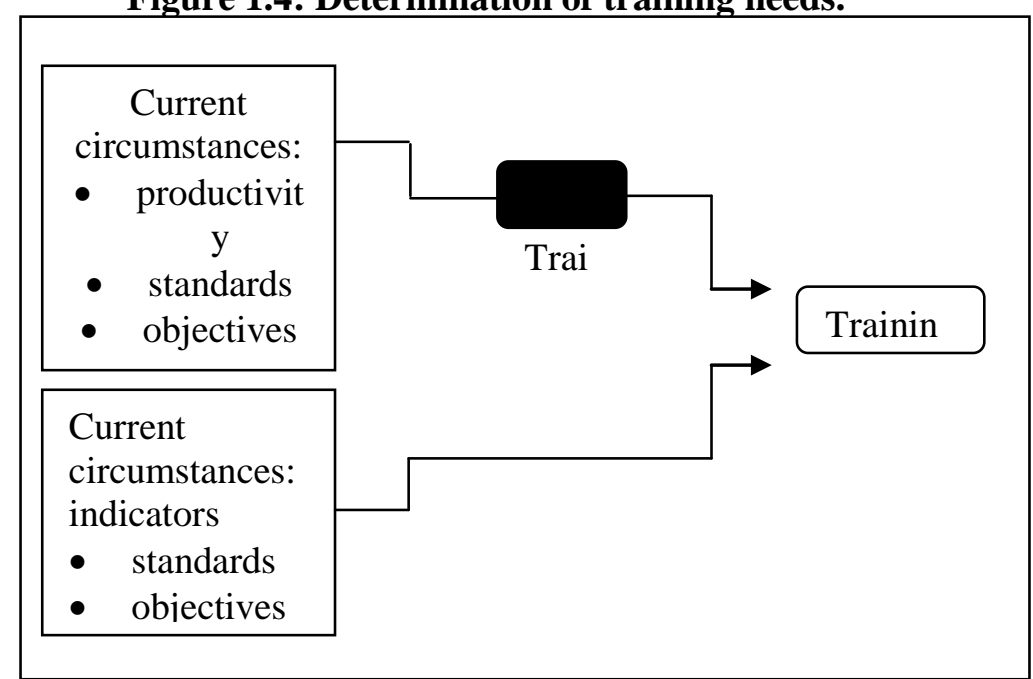

(a) Prioritizing training needs

- As part of training intervention, personnel administrators and managers need to identify the many training needs in an institution. The training needs identified must be arranged in order of relative importance to ensure that resources are used optimally.

- In spite of too many human and other variables influencing the process, however certain guidelines can be used, such as the following 
$>$ Legal requirements

$>$ Cost effectiveness

$>$ Requests from administration and management

$>$ Requests from public employees who do not perform up to standard

\section{(b) Techniques for determining public personnel training needs}

The complexity of the public management environment necessitates a scientific, integrated and systematic determination of training needs. Bernardin and Russell (1993: 298 - 301) and Reilly and Clarke (1990: 31 - 45) suggest three techniques that can be used to determine needs. These are: organisational analysis, job analysis and person analysis.

\subsubsection{Public personnel training objectives}

- Once a proper organisational or situational analysis has been undertaken, new objectives for the training programme can be formulated. It is particularly important to analyze the specific tasks and practices that public officials do and should carry out to improve them through training. Changing needs emerging from the situational analysis should determine the formulation of new objectives.

- By formulating training objectives, changes in behaviour and performance results through training are specified. The choice of content, learning opportunities and evaluation is meaningless if there are no objectives.

- Clearly formulated objectives enable course participants to direct their own efforts at achieving these goals and, as the person who formulates the objectives, the trainer and seriously consider what is to be accomplished in the teaching situation.

$\bullet$

\subsubsection{Planning structured training}

It is vital that training e structured and planned to ensure that its objectives will be achieved. Planning steps should be taken carefully to ensure that all variables in training are considered.

\subsubsection{Planning steps}

Three planning steps can be identified: (a) Situational analysis, (b) planning learning experiences and (c) the selection and arrangement of course content.

\section{(a) Situational analysis}

In the first step of designing a course, all the factors that can influence the proposed training programme (and the extent to which they may do so) are the course contents. The first important point in a situational analysis is that it is educational. The assistance and advice of specialists in the practice concerned should be used to identify the key elements of the knowledge and practices must have educational significance. The training needs of the department concerned or the public sector as a whole are also extremely important. The learning objectives of the course must coincide with the objectives of the department. The needs of the students (officials) should play a significant role in ensuring that unless and obsolete aspects will not be taught. Other things that should be taken into account in a situational analysis include: economic considerations, logistical provision of facilities and future projections concerning the practices.

The following factors should be considered.

- The trainer: Ire their style, experience, knowledge and attitude suitable for the training?

- The students (personnel): Factors such as sex, age, intelligence, study habits, motivation and work situation should be considered.

- The Training venue: The venue must be suitable for the type of training given. Things such as size, seating arrangements and noise levels play a significant role.

- Situational variables: The sociopolitical context in which training takes place should be considered so that the message can be adapted.

\section{(b) Planned learning experiences}


The purpose of a training programme is to facilitate teaching and learning and to link new experiences and practices with experience that has already been gained. In a situational analysis, the learning experiences that personnel have already gained should be determined to decide which ones to include in the new course.

\section{We learn by experience}

Preference should be given to learning experiences that can be related to problem solving and hands-on activities, since these experiences are easier to recall than mere facts which do not relate at all to the field of experience of the personnel.

\section{(c) Selection and arrangement of course content}

To compile the course content requires good subject knowledge wand the ability to select contents which will do justice to practice and which will meet the training needs of personnel. The course content is a selection and arrangement of learning content.

D. K. Wheeler (1976:218) uses the following criteria for selecting and arranging course content.

\section{Criteria for selecting and arranging course content}

- Validity: the contents must promote the objectives that they are supposed to promote.

- Significance: The fundamental ideas in practice must be represented by the selected content.

- The interest and needs: of the course participants (personnel) should be considered.

- Learnability: the level of presentation should be suitable for the

\subsubsection{Implementation and evaluation of training}

(a) Once the course has been developed, it must be presented. Preparation includes gathering relevant information on the topic and on the course participants. Knowledge of the participants is especially important in conveying the format of the message. Variables such as sex, age, language, culture, previous training, interest, attitude and motivation play a major role.

(b) Although the course participants should already be aware of the objectives they should know why they are attending the course, what they can expect from the trainer and what their duties will be. The following guidelines can be used for successful presentation of the programme.

\subsection{Implementation|}

\section{Criteria for successful presentation}

- Keep to the programme prepared.

- Maintain eye contact to ensure effective communication

- Vary the tone of your voice.

- Avoid iritating habits and movements such as swaying to and from, since they may break the course participants" concentration

- Use various relevant aids.

- Maintain a positive attitude.

- Allow time for questions to ensure that everyone understands

\subsection{Evaluation}

The final stage in designing a course is evaluation. Evaluation is used to determine whether the learning objectives have been achieved, whether knowledge has increased and whether changes have occurred in attitudes and behaviour. It is particularly important to determine whether one of the 
objectives - namely a change in behaviour - has been achieved. Did personnel acquire the necessary facts, knowledge, skills, attitudes and other outcomes that were formulated as objectives? The second purpose of evaluating it's to determine whether the experiences were suitable to achieve the objectives, or whether other experiences could have been used. Did the content contribute sufficiently to the achievement of the objectives? Were experiences and content integrated effectively?

Training intervention includes all the steps that we have discussed here. Note that the events in the cycle through to evaluation. If the evaluation indicates that the need for training has not been eliminated, the problem must be analyzed once again, and the cycle repeated until the problem has been solved. However, resources are limited in many institutions and not all training needs can be addressed immediately.

\subsubsection{Administrative and management development}

Administrative and managers are key decision makers who not only determine the survival of the institution but who can also have direct negative effect on the public through poor service. For this reason, administrative management development is an important priority for any institution to continue growing and adapting to changing circumstances. Administrative and management development is also necessary for individual career planning and to develop managers' skills to achieve the objectives of the institution. Development is essential if the best use is to be made of administrators and managers in an institution.

\section{Note that administrative and management development:}

- is planned and ongoing

- entails an improvement in skills and attitudes;

- must adapt to changing circumstances;

- takes place at all levels of administration and management.

It is also important to note that development can take place only if administrators and managers have a particular attitude - that is, the desire to improve and to be enriched.

\subsubsection{The need for and extent of public administration and management}

To ensure that there are always enough people to carry out advanced administration and management tasks, managers must be developed. Development programmes can be applied to people who have desire and therefore the potential to develop. Needs can be divided into macro- and micro-needs.

\subsection{Macro-needs}

- In countries such as Angola, Botswana, Lesotho, Mozambique, Zimbabwe and Zambia in southern Africa, resources are extremely limited, and it is vital to have effective administrators and managers who can use existing resources better so that more needs are met. Available resources are allocated through the implementation of the reconstruction and development programmes (RDP) and there is a shift in emphasis regarding priority. For example, funds for national defence have been reduced drastically in favour of education and health services. Southern Africa is developing subregion and development is taking place in a variety of areas. This means that arrangements must be made to make trained personnel available in all public institutions in order to meet increasing demands.

- The public sector has an obligation towards the public to improve the general welfare. The public therefore expects the best possible administration and management processes and services from public institutions. The demands for and standards of effective action are increasing all the time and public officials have to adapt. The need for training and development in this context is obvious.

Although training can be formal and informal, it must have a scientific foundation and be presented in an orderly fashion. Training and education culminate in development. Development is therefore simply an individual's move forwards on his/her own initiative after training, individuals cannot develop unless need to. In this discussion we will show the importance of and the need for training and development.

- The knowledge that you gain by studying this course will not mean that you are fully equipped to meet increasing demands and to address social problems successfully. Only if you

DOI: 10.9790/0837-2108022744 www.iosrjournals.org $\quad 41 \mid$ Page


motivate yourself to develop continuously will you keep pace with changing circumstances and address new problems successfully. We must emphasize that the training of today may not necessarily help to solve the problems of tomorrow.

\subsection{Micro-needs}

In the development process individuals must be equipped with certain knowledge, skills and attitudes. It is these skills and a positive attitude that administrators and managers need to carry out a task. A person needs to acquire certain skills (individual micro-need) and this is where the institution can make an input. E.B. Flippo (1983: 205) identifies six groups of needs that may arise in people with development potential are: (a) decision-making skills; (b) interpersonal skills; (c) job knowledge; (d) organizational; knowledge; (e) general knowledge; (f) Individual needs.

\subsubsection{A development for administrators and managers}

Bernadin and Russell (1993: 341) describe a development plan for administrators and managers as '.... formal, organized, planned effort to achieve a balance between individual career needs and organization workforce requirements'. It is a means meeting the current and future human resources needs of a public institution.

For a clear, overall framework of a development plan, Bernadin and Russell (1993: 341) suggest the following diagram.

Figure 1.5: Administrative and management plan

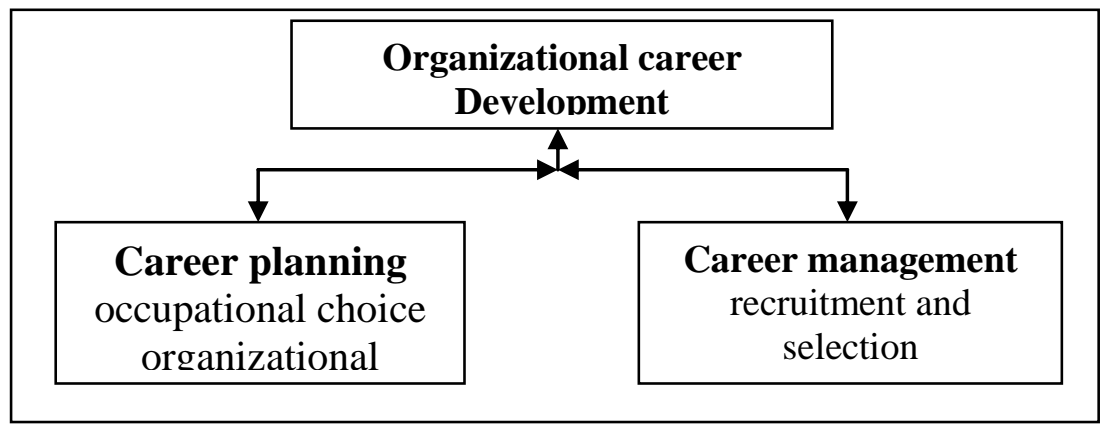

3.5.7.2.1.

Advantages of an administration and management development plan

Bernadin and Russell (1993: 346) list the following advantages of administration and management development plan.

For administrators and managers:

- Improved skills to manage personal career

- Greater retention of workers

- Improved communication between management and employees

- More realistic personnel and development planning.

- Productive performance appraisals.

- Better understanding of the institution's functions.

- More responsibility.

For the institution:

- Better use of management skills

- Improved dissemination of information at all levels.

- Improved communication within the institution

- Lower labour turnover

- Improved public image

- More effective personnel system

- Clearer objectives for the institution

\subsection{Steps in administration and management plan}


Certain formal and planned steps should be taken to ensure that the desired results in management development are achieved. Four main steps can be identified.

\section{- $\quad$ Step 1: Needs determining}

The first step entails determining current and future development needs and identifying target groups. Relevant and accurate information is vital for this purpose. The responsibilities and roles of employees, managers and the institution must be determined. Support systems in human resources management must be identified and implemented. The mission and philosophical foundation of the development programme must be formulated and a few methods for addressing the needs can be determined provisionally. Criteria and indicators for determining success must also be set.

\section{- $\quad$ Step 2: Vision}

Developing a vision entails determining a new direction and possibilities and creating a long-term philosophy for administration and management development. It is important that everyone be involved in developing a vision so that they can feel part of it. Career and support information must be given to managers so that they can manage their careers.

\section{- Step 3: An action plan}

The action plan entails a practical implementation plan. This requires commitment from top management. A pilot project is usually launched and evaluated first to ensure that resources will not be wasted by embarking on an unsuitable action plan on a large scale. The constant monitoring of available resources, such as finance and personnel, is essential. An advisory committee can be established to monitor the process, make recommendations, gather information and assist in designing the programme.

\section{- Step 4: Results}

A development plan must be integrated into the existing personnel training strategy. The results of the plan should be evaluated continuously. Bernadin and Russell (1993: 350) suggest that the following main elements be evaluated:

$>$ The degree to which objectives have been achieved, both at individual and organizational level;

$>$ The success of actions taken;

$>$ The positive change in output and productivity;

$>$ The degree to which attitudes and perceptions have improved.

It is also important to create a long term formalized approach to management development. Everyone must understand this approach. It must also be evaluated and redesigned.

\subsection{Mechanisms for administrative and management development}

Various mechanisms can be used to promote management development in an institution

- Self-assessment tools: include determining interests, attitudes, skills, personal short and long-term goals, strengths and weaknesses, and action plans.

- Career planning workshops: administrators and managers have assessed themselves; they can share their findings with colleagues in workshops. The feedback that t6hey receive helps them to learn important lessons from one another and to stimulate team spirit.

- Career workbooks: consists of questions and exercises designed to guide managers in identifying their own weaknesses, strengths, goals and career opportunities.

- Individual counseling: entails a private one to one discussion with a trained human resources cousellor. Personal weaknesses, opportunities and other aspects are discussed. Counseling is time consuming and therefore not always cost effective.

- Information services: managers must be able to take responsibility for their own careers. Internal communication systems can be used to inform personnel of promotion opportunities.

- Skills inventory: to ensure that all managers are used optimally, a survey must be made of their existing skills. This survey enables top management to determine whether people who have been assigned certain responsibilities are competent to perform them. It also indicates which managers can be promoted horizontally or vertically. A questionnaire may be used to gain general information 
and information on experience, educational background and level of skill. Tests can be used to determine aptitude - an element which cannot be ascertained effectively by means of a questionnaire.

- Development programme: these entail skills assessment and training programmes that institutions can use to develop managers. Some of the most commonly used programmes are the following:

$>$ Job creation - for gaining broader knowledge, skills and interest;

$>$ In-service training - which is practically oriented;

$>$ Assessment centres - which are particularly important for determining personal skills;

$>$ Mentoring - a competent manager guides another manager until he/she is able to perform a specific task independently.

\section{SUMMARY}

In this article, we focused on public personnel training with reference to Africa, most particularly southern Africa on account of its peculiar circumstances, on its necessity, the place and role of personnel administrators and managers in the public training process. It became clear that training has distinct advantages and that the public institutions cannot operate efficiently and effectively without it. We also indicated that training needs must be determined before training is given and that the training aims and objectives should coincide with the institutions' objectives.

Considering the scope, complexity and changing nature of public sector problems and the subsequent challenges facing public personnel administrators and managers, training is absolutely vital. Intensive training programmes should be developed to ensure that administrators and managers keep pace with the changing socio-economic-political environment. We also found out that administrative and management development is an indispensable part of any institution. Development prepares public personnel administrators and managers for further positions in the institutions. It requires a critical sense of responsibility from administrators and managers to meet their own developmental needs. Various techniques can be used for this purpose.

In the future, public institutions should be more imaginative, innovative, creative and enterprising, in finding ways for developing administration and management, since administrators and managers can no longer rely entirely on promotions and growth of the public institutions. The principles and practices of organization development and the learning organization can make definite and distinct positive contributions in this regard. In any case, training should be continuous and mandatory if development is to be sustained in any country.

\section{BIBLIOGRAPHY}

[1] Y. Andrews: The personnel function: Pretoria: Haum, 1988.

[2] D.S. Beach: Personnel: The Management of People at work: New York: MacMillan, 1985.

[3] H.J. Bernardin and J.E.A. Russell: Human Resources Management: An experiential approach: New York, Mc Graw-Hill, 1993.

[4] J.J.N. Cloete: Introduction of Public Administration: Pretoria: J.L. van Schaik, 1985.

[5] J.J.N. Cloete: Personnel administration: Pretoria: J.L. van Schaik, 1990.

[6] E.B. Flippo: Personnel Management, Tokyo: Mc Graw-Hill, 1983.

[7] S.B.M. Marume: Public Administration: special contemporary problems and challenges: Berlin, LAP Lambert Academic Publishing, 2015 [ISBN: 978-3-659-75883-9].

[8] S.B.M. Marume: The necessity of Personnel Training in Southern Africa: unpublished PhD degree programme: Academic work 12 B: California University for Advanced Studies, State of California, 1988.

[9] W. Fox and Ivan H. Meyer: Public Administration Dictionary, Juta and Company Limited, 1995.

[10] R. Harrison: Human Resources Management: Issues and Strategies: New York: Addison Wesley, 1995.

[11] D.D. Riley: Public Personnel Administration: New York: Harper Collins Publishers, 1993.

[12] S.P. Robbins: The administrative process: 2 edition, New Jersey: Prentice-Hall, 1982.

[13] F.A. Nigro and L.G. Nigro: The New Public Personnel Administration: 3 edition: Itasca, Illinois: F.E. Peacock Publishers, Inc., 1986.

[14] G.B. Siegel and R.C. Myrtle: Public Personnel Administration: concepts and practices: Boston: Houghton Mifflin Inc., 1985.

[15] D.K. Wheeler: Curriculum Process: London: Hodder and Stoughton, 1976. 